\title{
Just Societal Transformation: Perspectives of Pastoralists in the Lower Omo Valley in Ethiopia
}

\author{
Sabine Troeger
}

\section{Contents}

Transformation Toward Sustainability in Terms of Social Justice: Two Perspectives in

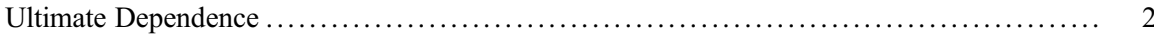

The Climate Change Imperative as Perceived and Acted upon by Pastoral Communities:

The Global Scale ....................................................... 5

The "Committee": A Pathway Toward Climate Change Adaptation and Mitigation? - The

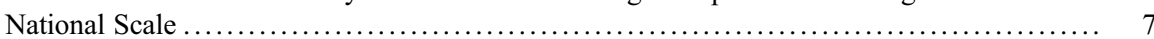

Large-Scale Investment, Irrigation, and Villagization: Opening the "Ground" to the State -

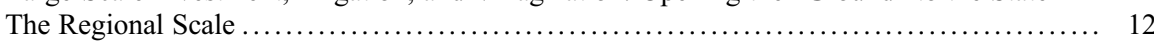

Climate Services, Pathways Toward Processes of Beneficial Societal Transformation? - The

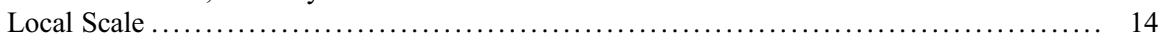

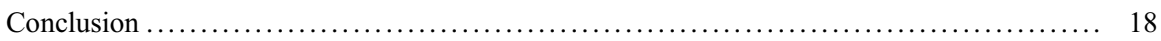

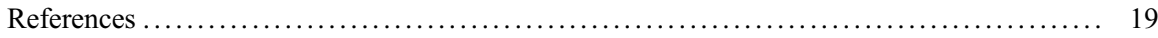

\section{Abstract}

Pastoralists' livelihoods in Africa are highly endangered by adverse forces - the climate change being one among those. Against this background, climate change adaptation is conceptualized as strategic agency in the field of risk-laden livelihood environments, that is, agency in the face of risky options and non-calculable uncertainties.

The chapter conceptualizes pastoralists' livelihoods exposed to a four-fold hierarchy of environmental risks and forces defining the actors' arena of strategic decision making: From the global scale of ever extending impacts by the climate change imperative, to the national scale of government policies in terms of decentralization, challenging people to govern and define their communal efforts in terms of climate change adaptation, and down to the regional scale,

\footnotetext{
S. Troeger $(\bowtie)$

Department for Development Research, Geography Institute, University of Bonn, Bonn, Germany e-mail: troeger@geographie.uni-bonn.de
} 
which in the presented case is dominated by a large-scale investment, the Kuraz Sugar Development Project, which again confronts local actors with adverse forces toward villagization and eviction from pasture grounds. Right at the end of this hierarchy and in accordance with discourses on "climate services," the end-users and local actors, the pastoralists, are confronted with and offered a product that they can input into their decision making: cattle feed from the residues of the irrigated sugar cane. The question remains whether substantive aspects of processes turning into true environmental and social justice in terms of recognition, procedures, and distribution will be paid attention to.

\section{Keywords}

Societal transformation - Climate services $\cdot$ Environmental justice $\cdot$ Riskscapes Decentralization · Land grabbing

\section{Transformation Toward Sustainability in Terms of Social Justice: Two Perspectives in Ultimate Dependence}

The notion of transformation is increasingly promoted in scientific and likewise popular discourses as a solution to unsustainable practices. Transformations toward sustainability are needed to address many of earth's profound environmental and social challenges. In transformational adaptation literature the distinction between incremental adjustments and transformational responses is to be found. As defined by the IPCC-Report 2018: "Global Warming of $1.5{ }^{\circ} \mathrm{C}$," incremental transformation refers to some means and instruments of "adaptation that maintains the essence and integrity of a system or process at a given scale," while "transformational adaptation implies "changes of fundamental attributes of a socio-ecological system." A transformative response to obviously unsustainable circumstances of life, be these ecologically or socially based, will require engaging with the root causes of inequality and likewise environmental degradation, which necessitates some transformational adaptation in the indicated sense. Furthermore, actions taken to shift socio-ecological systems toward more sustainable pathways can have substantial social impacts and may exclude members of communities from decisive processes.

The named perspective emphasizes the importance of contesting dominant social and political structures, rather than accommodating change to address the root causes of unsustainable systems and catalyze genuinely alternative futures. Transformations toward sustainability can only be taken as a success in case social justice is considered a central concern. In consequence, all actions taken to shift toward environmental sustainability can have both positive and negative social implications for different groups relative to the status quo, which means attention is needed to both understanding and realizing social justice during sustainability transformation (Temper et al. 2018). Following this notion three dimensions of 
justice are to be differentiated: (a) recognitional justice in acknowledgment of and respect for preexisting governance arrangements as well as the distinct rights, worldviews, knowledge, needs, livelihoods, histories, and cultures of different groups in decisions; (b) procedural justice with reference to the level of participation and inclusiveness of decision making and the quality of governance processes, and c) distributional justice, which can be defined as fairness in the distribution of benefits and harms of decisions and actions to different groups across space and time (Bennett et al. 2018).

Following the vision to turn scientific information from climate monitoring, research and modeling into operationally available information and services that would help societies to cope with climate variability and change, the World Meteorological Organization (WMO) launched the process for developing the Global Framework for Climate Services (GFCS) at the World Climate Conference (WCC) in September 2009. This conference recognized ongoing discourses on the unambiguous importance and relevance of climate services, which were considered essential to adaptation to environmental and climate variability and change (European Commission 2014). Climate services are to be seen as one essential contribution and element of transformations toward sustainability. But at the same time the perspective of climate justice identifies climate services as the source of a double inequality with a distribution of risk and responsibility (Adger et al. 2006, 2009). Climate services will mitigate the impacts of climate-related stresses, while the end-users' perspective is a key in tailoring the service measures (climateservices.org).

Against the background of these generalizing recognitions with relation to societal transformation in terms of environmental justice the chapter aims to explore the implications of present day environmental dynamics, the climate change intertwined with market and governance perspectives exemplified in their concretized meaning for pastoralism and pastoralist livelihoods in the Lower Omo Valley right in the south of Ethiopia: The Lower Omo Valley, until 2011 one of the most peripheral and likewise politically neglected regions of Ethiopia, has turned into a hotspot of societal transformation geared by natural, social, economic, and cultural forces. Home to 16 ethnic agro-pastoralist societies (recognized UNESCO World Cultural Heritage in 1980), formerly well adapted to the fragile semiarid environment of the lowlands, the Lower Omo Valley is nowadays highly impacted by irrevocable and fundamental changes in livelihood constellations caused by forces in a four-fold global to local scale gearing toward some ultimate and irrevocable societal transformation, that is, processes, which hold a strong grip on those ethnicities calling the Lower Omo Valley their home in terms of fundamentally re-defining the constituents of livelihood systems as of at present. With reference to the initial perspective of the chapter the argument will pose the question in how far and to which degree processes of transformation to be observed in the Lower Omo Valley are to be taken as sustainable, which includes the perspective of justice with reference to the addressed ethnicities, the pastoral communities in their distinct and unique representation. 
Grounded on actor oriented and constructivist reasoning the chapter subsequently relates to the perspective of human agency in the face of risky environments. Following Appadurai's concept of spatiality (1990), when he coins five terms with the suffix "-scape" indicating the ambiguity and fluidity of social phenomena, the chapter interprets agency by people in the context of their "social constructions" of their environments. The argument relates to the idea of "riskscapes" as defined by Mueller-Mahn and Everts (2018). Riskscapes are intertwined with social practices. The focus on practices posits that understanding human activity is key to any deeper knowledge of events and states. Schatzki (2002) emphasizes the fact that any practice involves various people and is always part of a larger set of socially ordered actions, highlighting the dynamic nature of social practices, how they change and how they relate to spatial and temporal dynamics. The argument follows Schatzki (2012:14), when he says, "a practice (...) is an open ended, specially temporally dispersed nexus of doings and sayings." Based on this recognition the concept of "riskscapes" refers to temporal-spatial phenomena that relate risk, space, and practice. Riskscapes link the material dimension of physical threats, like for example the climate change, the discursive dimension of how people perceive, communicate and envision risks, and the dimension of agency, that is, how people produce risks and manage to live with them. In consequence, risks are not to be taken "objectively given" phenomena, but are shaped and constantly modified through practices, which are socially embedded. Thus, observations in the field and with representatives of the communities in focus are to be understood in terms of agency in recognition of people's perceptions, interpretations, and evaluations of their environments.

The chapter elaborates on four perspectives of given environmental - natural as well as social and sociopolitical - constellations and livelihood frameworks in scales in the Lower Omo Valley. The argument will draw the attention to two comprehensive conclusions of these observations and assessments in the field, to subsequently link these with regional forces in terms of villagization and sedentarization policies, which are taken as "dispositives" as understood by Foucault (1977). In line with this understanding, present and pressing development perspectives are outlined, which highly challenge and tackle the field of environmental justice. Concluding, the argument will revise the field and discursive findings with relation to the four analytical scales and suggest some rounding up picture of the observed societal processes in terms of a transformation answering the claim to social justice.

Figure I titled "Societal Transformation" illustrates the above referred to analytical concept in scales: 


\section{Societal Transformation}

\section{Dynamics in Scales - Lower Omo Valley/Ethiopia}
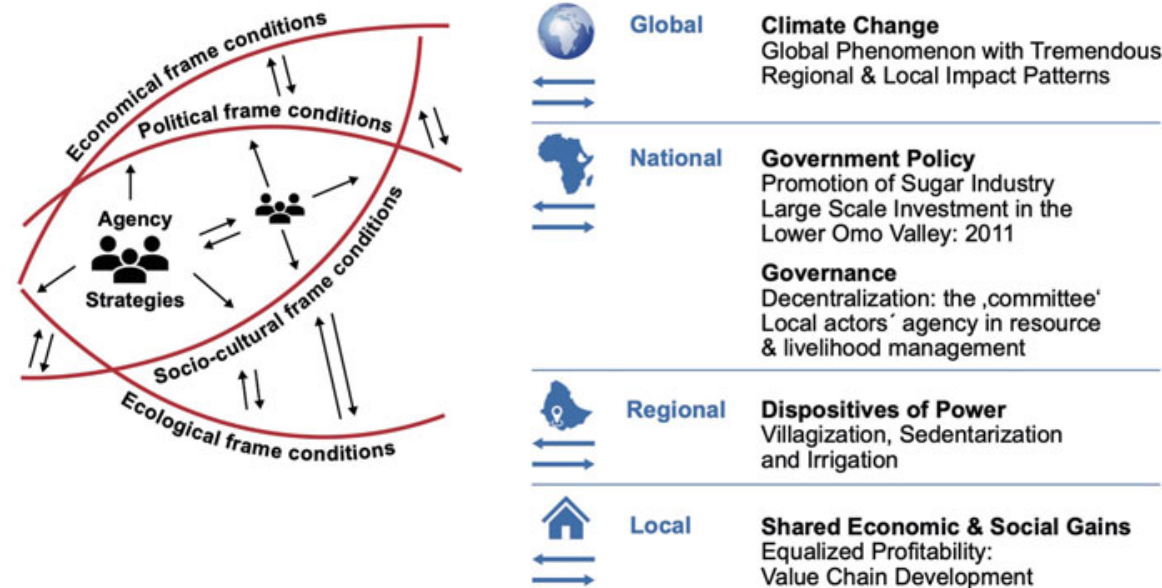

Concept: Sabine Troeger, model modified with permission from Theo Rauch (2003)

Figure I: Societal Transformation, Dynamics in Scales - Lower Omo Valley/Ethiopia (source: Concept Sabine Troeger, model modified with permission by Theo Rauch -2003 )

\section{The Climate Change Imperative as Perceived and Acted upon by Pastoral Communities: The Global Scale}

Data from the field leave no room for doubt about the severity of ongoing and in the course of time further enforced climate change impacts in the Ethiopian Lowlands (Troeger et al. 2012). The Lower Omo Valley, located in the southern part of these lowlands, is highly exposed to a climate change pattern characterized by considerably shortened Belg rains as part of the customary rainfall pattern. These were formerly expected to be starting end of February or early March and lasting until end of May or beginning of June. The eastern and southern regions of Ethiopia, demarcated by the Rift Valley, are highly dependent on this specific rainfall pattern for their annual agricultural production as well as their migratory routes with their livestock, which in this case is cattle, whereas the goats and sheep, the smaller ruminants, remain with the women, the wives, children, and elderly people. They will feed on the pastures and bush-vegetation in the vicinity of the homesteads, which are rhythmically shifted within a radius of some kilometers but remain in line with the pastoralist livelihood system more or less concentrated on some an ethnically defined neighborhood.

At the time of the field assessment the pastoralists discussed the spatial and quantitative changes of temperature, precipitation and floods. To their perception, all of these un-contradictorily stated deviations and irregularities in rainfall started 
around the year 1989 and since then have shown a gradual decline in precipitation. More severe changes were perceived to have started after 1998 and culminated for the first time in the year 2011, when large parts of the Horn of Africa were struck by one of the worst droughts ever recorded in 60 years, which translated into a severe food crisis. In July 2011, the United Nations declared a famine, but already as early as January 2011, considerable heads of livestock had died, as reported by the people. The drought that started in 2011, whether it was caused by global climate change factors or the effect of a very harsh La Niña event as suggested by IRIN News (15 July 2011), took place in the wake of 4-5 years of more or less failed Belg rains, as summarized to be a general trend by the diagram below:

\begin{tabular}{|c|c|c|c|c|c|c|c|c|c|c|c|c|}
\hline & Jan & Feb & Mar & Apr & May & Jun & Jul & Aug & Sep & Oct & Nov & Dec \\
\hline $\begin{array}{l}\text { Bef. } \\
1989\end{array}$ & & & & & & & & & & & & \\
\hline $\begin{array}{l}1989- \\
1998\end{array}$ & & & & & & & & & & & & \\
\hline $\begin{array}{l}\text { After } \\
1998\end{array}$ & & & & & & & & & & & & \\
\hline \multicolumn{13}{|c|}{ Legend } \\
\hline & $\begin{array}{l}\text { Daily } \\
\text { Rain } \\
\text { Rain } \\
\text { Rain } \\
\text { Onc } \\
\text { Unre }\end{array}$ & $\begin{array}{l}\text { ains } \\
\text { very } \\
\text { very } \\
\text { nce } \\
\text { a we } \\
\text { ability }\end{array}$ & $\begin{array}{l}\text { secon } \\
\text { secon } \\
\text { it twice } \\
\text { of } \\
\text { of rain }\end{array}$ & $\begin{array}{l}\text { d-thi } \\
\text { a thi } \\
\text { ano }\end{array}$ & $\begin{array}{l}\text { rd day } \\
\text { rd day } \\
\text { eek } \\
\text { lear } p\end{array}$ & attern) & s relic & ble) & & & & \\
\hline
\end{tabular}

Figure II: The Climate Change pattern as perceived and acted upon by the people. (Source: Troeger et al. 2012)

"Everything that is happening now, is beyond our capacity" was the unisonous statement of the people, be these young or old, when talking to them in the field. The conclusion drawn by Moro, at that time Nyangatom women leader, summarizes the research findings (Troeger et al. 2012) and unambiguously indicates a livelihood configuration highly at risk, going hand in hand with a dissolution of beforehand sustainable codes of conduct, namely the indigenously established "culture of sharing," when people deliberately and spontaneously shared food and further agricultural produce and items (Troeger 2016b \& 2018). 
A concordant climate change pattern showed the precipitation and subsequent constellations of food crises in the past year, the year 2019, which can be taken as an

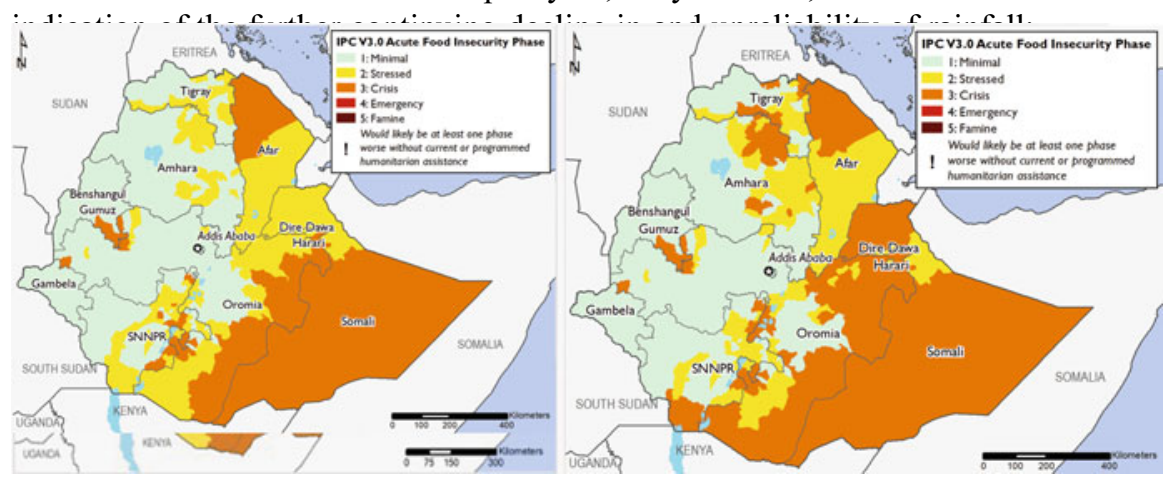

Figure III: Patterns of food Insecurity in the wake of deficit precipitation in the Lowlands - the year 2019. (Source: with permission by Famine Early Warning Systems Network (FEWS.net))

Moving back to the initial question of people and pastoralists in confrontation with processes of environmental risk and transformation, pastoralists in the Lower Omo Valley see themselves and are to be taken as threatened beyond their formerly established coping potential. According to their reports the young herders could not follow their seasonal migratory pattern among other things. There were reports about young herders, who stayed away from their culturally manifested neighborhood for several seasons in succession. People were worried about these environmental tendencies and complained that, as the weather got drier and it became increasingly difficult to survive, neighborhoods fell apart, people abandoned their traditions and were forced to accept other lifestyles (Troeger et al. 2012).

\section{The "Committee": A Pathway Toward Climate Change Adaptation and Mitigation? - The National Scale}

Turning to the national level, the argument moves on from the following observation:

Following the agenda of the government, the claim of "development" has always been and is as well with the new policies guided by the present Prime Minister Abiy Ahmed the directive of the rulers of the state. Governments' interventions labeled NRM, natural resource management, combine hegemony and governmentality projects to conform citizens into its governmental state ideology. While local governments continue to be representatives of the controlling apparatus of the political elite rather than representatives of interests of their constituents (Ayele 2011), they will follow the "development narrative." Party loyalty is demonstrated by adopting agricultural ideas promoted by the state, which is indicated by Lefort (2012), who suggests that so-called model farmers are rather party agents instead of famers with high agricultural competence. 
Based on this insight the political role of "committees," coinciding with the claim for decentralization all over Africa and together with the mainstreaming of participatory approaches in development practice, is to be questioned. Do communities experience a shift in policies to advocate local actors and resource users and play a more active role in natural resource management (NRM), which in many cases today is to be understood as climate change adaptation (CCA)? Decentralization in general describes the process by which bundles of entrustments, like regulatory and executive powers, responsibility and authority in decision-making, are transferred to local agents, which again calls for new institutions and processes of institution building, that is, the committees. The following argument digs deeper into this perspective of local policies and into the perspective of "handing over the stick," the guiding principle of the participatory approach in development practice PRA and of governance in local contexts. And at this point, the question of environmental justice becomes vital as the impact of decentralization is to be measured with respect to recognitional, procedural, and distributional just and fair outcomes relating to actors and activities on the local scale.

The targeted processes of decentralization come about in the shape of "committees," that is, institutional settings, which have mushroomed up in various development contexts all over Africa. Activities of the "Western" ideal of democracy in the shape of committees focus in general environments of obvious global change, which force local actors to unanimously and fundamentally adapt to the irreversible changes in nature. Informed by this perspective, the committees mirror the principal idea of equal representation and equal voice. Per definition has the ideal of "participation" developed to be the counter-balance to the sociopolitical institution of "committees," which again claims to "give people a voice." In consequence, the notion of "voice" unambiguously links the concepts of "committee" and "participation" with the need for "communication," true communication, which enables intersubjectivity via a mutual exchange of people's perceptions, interpretations, and valuations, in short: social constructions. In summary, committees are taken to be the platform for participation in realization of the demand for "communication" regarding "giving people a voice."

Corresponding with Government policies in promotion of sustainable and decentralized community development in Ethiopia, a "committee" has been established with the Nyangatom community. The Nyangatom are one of the 16 ethnicities in regional focus. Their committee was explicitly established to safeguard and control the recently established scheme of rangeland enclosures in support of climate change adaptation needs in terms of referred to propagated improved land use techniques. Rangeland enclosures, enclosed by bush thorn fences, are manifestations of private landownership, which excludes members of the community from participating in the advantages of the protected grazing areas behind the fences. In consequence, parts of the former "commons" are claimed by the powerful representatives of the communities. The committee was first installed in order to govern the new scheme on local grounds and resist against the powerful take over by some community members. But very soon after it was appropriated by Government employees, by "experts" from Addis Ababa. 
In contradiction to the outlined and to our "Western European" eyes normalized and customized ideal of democracy the established committee meets societal constellations on the ground, which had known and were based on some means and ways of mutual consensus finding by their own constitution. The Nyangatom, one of the unique pastoralist ethnic groups of Ethiopia's south, situated in the Lower Omo Valley, numbering about 10,000 people, has like its neighboring pastoralist communities, ever since been guided by an "age-group system." The system is constituted by five age groups: children, youths, herders of 25-50 years, the political class of the "elephants" aged 50-65 years, and the very old and wise men in the role of spiritual guides, as explained by two community guides:

The elders used to manage the grazing land by telling the herders to shift from pasture to pasture. They sent young herders to check the condition of the grass, and then they decided on the migration paths. If someone was seen taking his animals to the forbidden areas, he would be punished. But punishment is not constant. It will vary from people to people and it depends on the severity of the action. But it as well respects the livelihood constellation of the trespasser and defines the punishment in accordance. (Soya Kurupa, man - 14 March 2015, approx. 42 years) (Troeger 2018)

The cultural management has no written rules and regulations, because once the elders pass the decision, no one will disobey. It is a management, where everyone has to obey. We have grown up with it, so we like it very much. (Moru Lomarle, woman - 12 March 2015, approx. 55 years) (Troeger 2018)

Interpreting village-level ethnographic data from the named pastoralist livelihood scenery, the case of the Nyangatom, the chapter supports the following thesis: The formula of "transformative adaptation," as propagated by, for example, the 5th IPCC assessment report 2014 and likewise by the report on "Global Warming of $1.5^{\circ} \mathrm{C}$ " (see above) with some successful climate change adaptation in view, and subsequently multifold suggested by initiatives hailing processes of societal transformation, does not necessarily gear toward a change in the name of a more resilient and sustainable development. Field data reflect on interpretations and perceptions by the pastoralists involved relating to this transformative impetus. They indicate "disagreement in the shadows" as defined by Rancière (1998), and a disruption of processes of communication and mutual cooperation. With this portrayal Rancière indicates some community constellations, which do not allow for open resistance but only offer some hidden away and not openly articulated opposition (ibid.).

Listening to the people, to "the people's voice," reveals the true process lines of the committee meetings and offers the chance to get closer to the meaning of "governance" and "participation" facilitated by processes of communication in given frameworks of the committee. Perceptions and interpretations are singled out in line with the perspectives of: "structural forces and governance," "modes of participation," and "articulation of social correctness."

I myself had the idea of establishing rules to govern our problems with the drought and the use of the pastures, but then I heard that the Woreda people are coming to establish the rules and regulations. And there were some people from Addis Ababa, who gave us some papers, 
which listed the rules. They asked the people to add on it, and of course, everything was clear, and nobody added anything on top of the by-laws, and the committee was selected from different age-groups. (Lobowa, approx. 42 years - 14 March 2015) (Troeger 2016b \& 2018)

Quite in line with the general articulation of the "development narrative" in Ethiopia, obviously no participation, which could indicate true "governance," had been sought. The community member claims initially own, self-determined ideas about necessary regulations, but he had no chance to promote these tentative frameworks of governance. No "freedom to articulate one's own voice" is given in this process of communication. No recognitional nor procedural justice is given to him and his ideas. He is neither respected in his worldviews, knowledge, and needs, nor is there any true chance for true participation offered to him. The message from the district and national governance representatives turns out to be an unambiguous top-down message, which has to be "swallowed" by the people on the ground, by those, who in future would be the ones to realize these handed over regulations. Structural forces govern the information instead of true communication processes. No communication in the ideal sense is realized, which is even more emphasized by the following statements:

Us elders, we were unsure whether to accept the new rules, but the Woreda people made us accept the idea of bye-laws. (Dida Lolibes, man - 11 March 2015, approx. 64 years) (Troeger 2018)

The leaders from the Woreda and the people from Addis made us discuss the question of the punishment for not following the rules. So, the discussions were led by the experts, and they were the ones to give a speech on the positive side of the new governance system and make the community accept the idea. Even me, I accepted it. (Ariapa Lokitibo, man - 14 March 2015, approx. 38 years) (Troeger 2018)

By listening to the people's voice it becomes obvious that the modern idea of committees will not match with the culturally established and believed in articulation of authority and representation. The idea puts the indigenous identity at risk. The articulated obedience toward culturally manifested rules represents customary regulations and a sense of belonging and identity. Especially the emphasis on a fair, socially reflected and balanced execution of established rules and regulations contrasts the perception of today's realization of power and authority. The obvious notion of "disagreement" indicates a situation, when meant to be partners in communication do not necessarily contradict each other openly but disagree in the shadow of claimed consensual modes of governance. On the surface, this consensual governance has reduced political conflict and disagreement (Swyngedouw 2011), but in reality, the partners in communication have not reached a common ground of understanding. "Disagreement in the shadow" should be taken to the open and made understandable to all. The new challenges and arrangements with relation to the range enclosures and in consequence processes of commodification of the "commons' are to be discussed and reflected on mutually and in an atmosphere of mutual freedom of articulation. But this disposition cannot and will not be found in a 
situation, when the inherited and traditional authority of the "elephant" age group is confronted with some authority of the government in regional and national contexts.

The so-called "participatory" processes in the pastoralist communities does not only confront the people on the ground with readymade answers and new regulatory frameworks but excludes some members of the community completely from the wished for democratic process. They are put at risk. Thus, neither some "equal grounds of understanding" nor any "freedom to articulate one's perceptions" and evaluations of the given social needs in terms of a fair and transparent handling of the new "structural forces" in the shape of the climate change imperative is sought for:

My neighbors in our settlement did not participate in the discussions. According to what I now know they are not happy with the decisions because they did not get any clarification on this matter like we did from the Woreda and the people from Addis. (Ariapa Lokitibo, man 14 March 2015, approx. 38 years)

The example of the Nyangatom pastoralists in south Ethiopia unambiguously highlights given processes of communication to be by far not manifested in the open and freed from structural power. Communication in the committees is dominated by "experts," that is, the agents of the government following the "development narrative" as outlined above. The actors on the ground resisted the officially outlined principles and practices of climate change adaptation "in the shadow": "We should take disagreement to mean a determined kind of speech situation: one in which one of the interlocutors at once understands and does not understand what the other is saying. Disagreement is not the conflict between one who says white and the other says black. It is the conflict between one who says white and another who also says white but does not understand the same thing by it or does not understand that the other is saying the same thing in the name of whiteness" (Rancière 1998).

Essentially, this argument proposes that governing climate change has been characterized not only by disagreement, but climate change communication in this case is to be understood as subcutaneous resistance, voiced quietly and under cover, stating in the end some ultimate failure in communication. With reference to the differences in an articulation of social justice as defined above the committees in today's shape are not to be understood as windows of opportunity toward more environmental justice and sustainability in societal transformation. Mouffe (2013) links to the reflections of Rancière (1998) and Swyngedouw (2011) referred to above, when she states: "We have to relinquish the claim that the processes of democratization should consist in the global implementation of the Western liberal democratic model ... the kind of individualism dominant in Western societies is alien to many other cultures, whose traditions are informed by different values. Democracy, understood as 'rule by the people', can ... take other forms - for instance, forms in which the value of community is more meaningful than the idea of individual liberty."

The argument summarizes observations in the field accompanied and highlighted by the voices of the local agents stated above and objects to any claim of social justice granted to these agents, the pastoralists. The process of decentralization is not 
to be taken as any granted path toward true communication with effective recognition of all community members on equalized grounds. Accordingly, the challenge to reach some just and in this way sustainable societal transformation is not responded to in any meaningful terms of governance.

\section{Large-Scale Investment, Irrigation, and Villagization: Opening the "Ground" to the State - The Regional Scale}

Turning toward the regional scale, the argument links to the frequently quoted statement by the late Prime Minister of Ethiopia, Meles Zenawi, the sociopolitical meaning of which is to be considered one of the most crucial turning points toward the situation of societal transformation as of today: "I promise you that, even though this area is known as backward in terms of civilization, it will become an example of rapid development" (Meles Zenawi speaking at the Pastoral Day Festival in Jinka, South Omo Zone, 25 January 2011).

The first "state" representation in the Lower Omo Valley times back to the 1960s, when programs of sedentarization and the establishment of the Omo National Park (1966) and the Mago National Park (1979) led to increased resource pressure for the agro-pastoralist ethnic groups, traditionally inhabiting this area and using its resources for pastures for their livestock and especially the river banks for river retreat agriculture. Soon after, that is, in the 1980s, the then Ethiopian military regime released the Omo Basin Development Plan and in this context initiated the construction of the Gibe III hydro dam north of and at the entrance of the Lower Omo Valley, the construction of which was started in 2008 and the filling of which was completed in 2016. Today, the Gibe III dam is to be taken as the most influential structural incentive of those transformative forces and risks, which have defined and continue to define life and the livelihood systems in the Lower Omo Valley.

Relating to Meles Zenawi's argument, commercial investment processes were predicted and initiated, which turned Ethiopia and especially the pastoralist lowlands of the country into a hotspot of what commonly is called the "land grab." By emptying Ethiopia's pastoral lowlands for large-scale investors, in the case of the Lower Omo Valley the Kuraz Sugar Development Project (KSDP), the ground was opened for police and military, for the "state," giving protection to these investors. The establishment of the large-scale investment was sidelined and backed by the implementation of new agricultural technologies in settling and sedentarizing pastoralists in relocation sites by providing them with agricultural extension packages in terms of chemical fertilizer schemes, improved seeds, which the pastoralists had to pay for, and small parcels of irrigated land (Regessa et al. 2019). The government deliberately claimed the culturally inherited pastoralist land, the "commons," for investments, as it was considered "underutilized" and "unproductive," as the pastoralists were interpretated not "civilized" enough to make appropriate use of it. This villagization program, officially known as Mender Masebaseb, meant some fundamental transformation to the pastoralists - they were supposed to become and be 
sedentary and give up or at least considerably reduce the basis of their livelihood system, their seasonal extensive cattle drives and migrations.

The Lower Omo Valley, South Omo, in historical times was and up to now is to be taken as an environment of latent and open social conflicts, conflicts on various levels and with reference to diverse agents and contesting parties. The 16 agropastoralist ethnic groups find themselves in partly violent competition on grazing grounds and heads of cattle. These conflicts have largely been analyzed by anthropologists like David Turton (1985) and Jon Abbink et al. (2014). Nowadays, since 2011 , since the valley has turned into a region of high national interest, the local manifestation of the Government-owned Kuraz Sugar Development Project has opened new grounds for conflicts including human rights violations. About 90,000 people in the Lower Omo valley had been depending on flood-retreat farming for sorghum cultivation along the Omo (Turton 2010). In the more southerly parts of the Lower Omo the areas flooded by the river were larger, while the people on the surrounding plains were even more reliant on flood retreat farming than their neighbors in the north, as these practice rain-fed agriculture. Since the end of the Omo floods in 2015, most groups in the northern part of the Lower Omo Valley have become entirely dependent on rain-fed cultivation for crop-production, which leaves them highly vulnerable to climate change induced droughts, or solely dependent on corporation-controlled irrigation systems (Stevenson and Buffavand 2018). Furthermore, reductions in the river flows downstream of the sugarcane plantations are taken to reduce the availability of water - moisture in the soil - with damaging effects on the pastures for the pastoralists' livestock, especially cattle and sheep, while goats are browsers and can partly feed on bush vegetation. Land clearance for sugar plantations has additionally restricted wildlife in vital habitats and cut people's access to subsistence opportunities (Buffavand 2016).

In conjunction with the dam, a system of canals has been built to distribute water to the Omo-Kuraz Plantation, within which selected plots of land have been assigned for use by "settler pastoralists." At full capacity the Kuraz production sites would realize, this the initial projections, a quarter of Ethiopia's sugar and ethanol production, more than any other sugar production site in the country (ESC 2014).

KSDP operates on about 100,000 ha production sites of sugar cane, the formerly pastoralist "commons," irrigated by water from the Gibe III hydrodam. In conjunction with the dam, a system of canals has been built to distribute water to the OmoKuraz Plantation, within which selected plots of land have been assigned for use by "settler pastoralists". At full capacity the Kuraz production sites would realize, this the initial projections, a quarter of Ethiopia's sugar and ethanol production, more than any other sugar production site in the country (ESC 2014). The sugar cane is, or will in near future be processed in up to five sugar factories lined along river Omo and situated in pastoralist territories. What is happening in the Lower Omo Valley combines elements of different types of displacement. The scheme was planned and executed by the current regime in Ethiopia in collaboration with an Italian engineering firm and international financiers. In 2012, the South Omo Zone Agriculture Bureau promoted a "Villagization Plan," which described how and when in the course of the coming year the people would be moved into new villages (FDRE 
2012). In the plan the benefits of villagization are described as follows: "growing new crops, such as sugarcane on irrigated fields would improve food security; providing people with schooling and medical services would improve their health; settling in planned villages would reduce conflicts that result from "mobility in search of water and pasture". ... "In the case of land that relies on rain (for cultivation) 2 hectares would be appointed to each settler pastoralist, whereas those settling on irrigable land would be appointed 0.5 hectares each" (FDRE 2012).

In contradiction to these positively connoted outlooks, findings from the field by E. G. J. Stevenson and L. Buffavand (2018) indicate that crop yields were and will be by far not sufficient to feed the pastoralist settlers, let alone to produce a surplus for sale. "... villagization was actually experienced by the Bodi settlers as undermining food security and diminishing well-being. It was experienced as heat, as disruption of routines, as a loss of control over livelihoods, as being treated like children rather than adults, and as abstracting work from ordinary sociality" (ibid). In congruence with these findings the study on "Social-ecological change in the Omo-Turkana basin: A synthesis of current developments" by almost the entire group of researchers active in the Omo-Turkana basin (Hobold et al. 2019) recapitulates their findings in a sense of comparative winners - the migrant laborers - and losers - the indigenous peoples (including both agro-pastoralists and pastoralists, but with more borne by agro-pastoralists currently): "Important SES-wide impacts will result from changes in regulating, provisioning, and cultural ecosystem services, including potential environmental degradation; loss of biological and cultural diversity; heightened competition and conflict over natural resources; and the potential for increased dependence on food aid" (ibid.). The other major actors - agro-industry investors, and the governments of Ethiopia and Kenya - they classify as in an equivocal position, with potential for large gains, but also exposure to substantial risks - a position, which is highly contradicted by one of the authors - Benedikt Kamski - at another place. In his argument titled "Omo investors won't scrub away Kuraz's sugary stain" (Kamski 2019) he states: "ESC (Ethiopian Sugar Corporation) rushed into the multi-billion dollar project, largely neglecting critical feasibility and impact assessments" (ibid). The author stresses the urge ESC is experiencing when the capital-intensive transformation of the region failed to bear fruit for its indigenous communities, which in turn creates new conflict dynamics. He concludes: "If economic interests alone guide investment decisions, official visions for inclusive pastoralist development - as recently reiterated by Deputy Prime Minister Demeke Mekonnen - will require additional effort and financial commitment by the government, and a big question mark remains over whether this will materialize" (ibid.).

\section{Climate Services, Pathways Toward Processes of Beneficial Societal Transformation? - The Local Scale}

As indicated above, the chapter will now and finally turn toward and highlight some projected initiative in terms of climate services towards a promotion of livelihood security and environmental justice in favor of the indigenous inhabitants of the 
Lower Omo Valley, the pastoralist societies. The reasoning of this perspective responds to the again and additionally outlined and named below livelihood risk and conflict scenarios taken to be highly virulent and tangible.

Upon the time and again scheduled and rescheduled completion of the Kuraz Sugar Development Project (KSDP) the overall about 800,000 ha pastoral land will be reduced by 100,000 ha. The sugar production was from the very beginning meant as vehicle of state governed development and progress. But, in spite of the major cutbacks in size and processing capacity, has the KSDP highly impacted on the livelihood system of the pastoralists (Kamski 2019; The Oakland Institute 2013). River Omo is nowadays framed by about $15-\mathrm{m}$ broad irrigation canals, which hinder traditional use of water by the pastoralists for animals and river bench agricultural cultivation. As the pastoralists had to give way to the sugar plantations, they were called to re-settle in newly established permanent villages - the "villagization program" driven by Government policies. In the course of the thus induced transformation processes, many pastoral households are nowadays facing a livelihood situation of food-insecurity. In need of watering their livestock the pastoralist herders are nowadays forced to virtually beat their animals through a dark subway underneath the bottom of the irrigation canals, the so-called underfly. As the floor of these subways is moody and slippery, herders complain about injured cattle with broken legs. Lacking mostly veterinary services in the pastoral setting of life herders will eventually feel forced to kill their injured animal (Pictures I and II).

Additionally, and along with the establishment of the sugar plantations some extensive labor force was needed. Up to today, about 30,000 migrant laborers have arrived from the Ethiopian Highlands. Moreover, re-settlers from the highly populated areas of, for example, the Konso in South Ethiopia have taken advantage of the labor demand in the sugar project. The number of migrant laborers is expected to reach some hundreds of thousands, when all production sites and the five sugar factories will be fully operational (Kamski 2016).

Against the depicted situational setting, resource-based conflicts and at times violent encounters are and in future will be the "order of the day." In the course of

Picture I The example of one of the two irrigation canals along both sides of River Omo (source: with permission by Omo Turkana Research Network (OTuRN 2016)

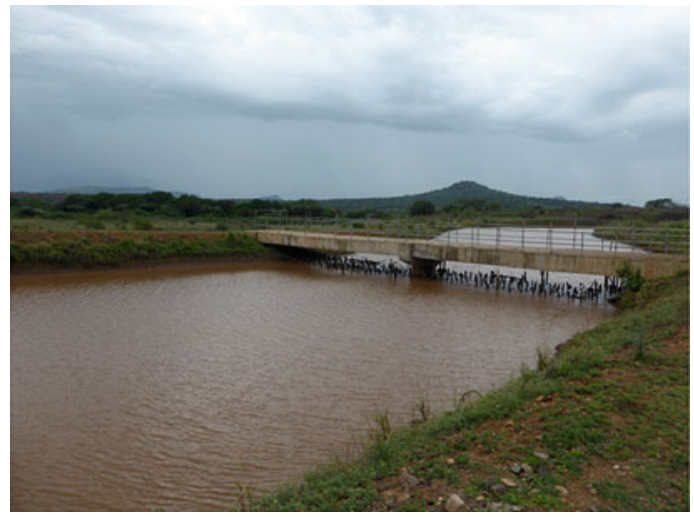


Picture II One of the 'underflies', the only paths for the pastoralist herders to drive their livestock for watering (source: with permission by Omo Turkana Research Network (OTuRN 2016)

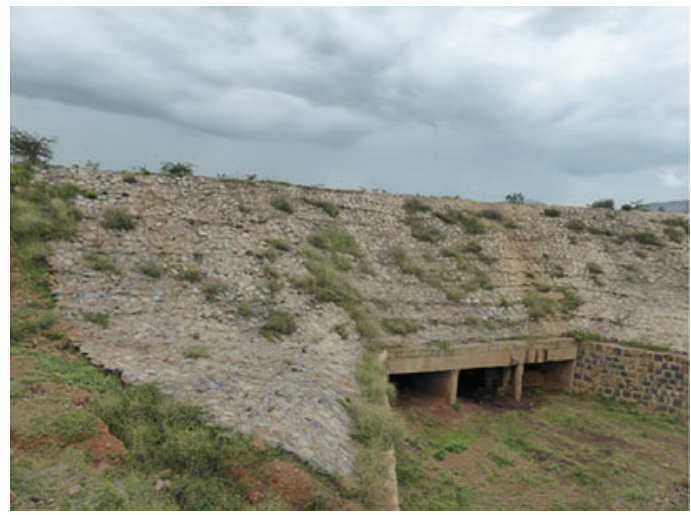

resource - land and water - scarcity, the agro-pastoralists ethnicities find themselves squeezed by natural factors (climate change) and the sugar cane development project. Hence, some growing resentment and animosity toward the dominance of the sugar project and some resistance against the migrant population are poisoning today's encounters between the diverse interest groups. The pastoralists feel treated unjustly and surely suffer from a lack of recognitional as well as distributional justice.

Moreover, resource scarcity has increased the intensity and frequency of interethnic conflicts among the agro-pastoral ethnicities. If not solved, the current tensions and violent confrontations are likely to engulf the entire South Omo regional entity - one of Government's perspective development corridors in Ethiopia.

In summary, food and livelihood security of the agro-pastoralists in the Lower Omo Valley have become highly vulnerable. This relates on the one hand to the considerable impact of climate change in the course of which the Belg Rains fail several seasons in succession as outlined above but likewise to the reduction of freely accessible pasture land in the course of the establishment of the sugar production sites and thus the reduced option in shifting cultivation in comparison to former times. The anchor element of this setting is "feed for the cattle," the central economic and likewise sociocultural value in pastoralist livelihoods. With relation to this socioeconomic "anchor element" in question, the agricultural value chain of the produce sugar cane moves into focus. This value chain is centered to be the protagonist of conflict mediation and resolution in its function to smoothen livelihood stress and vulnerabilities. It is meant to be the manifestation of climate services applicable in given contexts.

In the course of the following argument some design shaping a rather realistic feature of climate services was outlined in 2019, but seemingly has not been realized up to now. As pointed out above the following discussion will in consequence be somehow speculative - but all the same realistic. The envisioned scheme of climate services targets the given lay of conflicts between the indigenous pastoralist 
communities and the Ethiopian Sugar Corporation (ESC) by one central element: by cut-off residues, bagasse, and molasses from the sugar cane, by-products from the sugar production - to be turned into cattle feed. A project like this would be conceptualized as "contract research," with high emphasis on the value chain development of the sugar cane, but likewise with explicit focus on various social perspectives on conflict resolution, discharging into a process of integrative societal transformation (Picture III).

Guided by the promoted Government politics in terms of "ethnic reconciliation" the project could operate on value chain development and open access to cattle feed for the pastoralist ethnicities. New environments of coexistence among the interest groups in question on equalized grounds were to be defined and processes of integrative societal transformation to be eased.

It can be foreseen that climate services as outlined above bear dangers in terms of some processes of fatal societal transformation, as will be outlined as follows: Indigenous pastoralist societal organization does by its concepts of live and livelihood constituents not incorporate the idea of feeding and, even much less, fattening cattle, whereas the government program of villagization claims the idea of sedentism

Picture III A herder with his favorite ox (source: with permission by Julia Pfitzner)

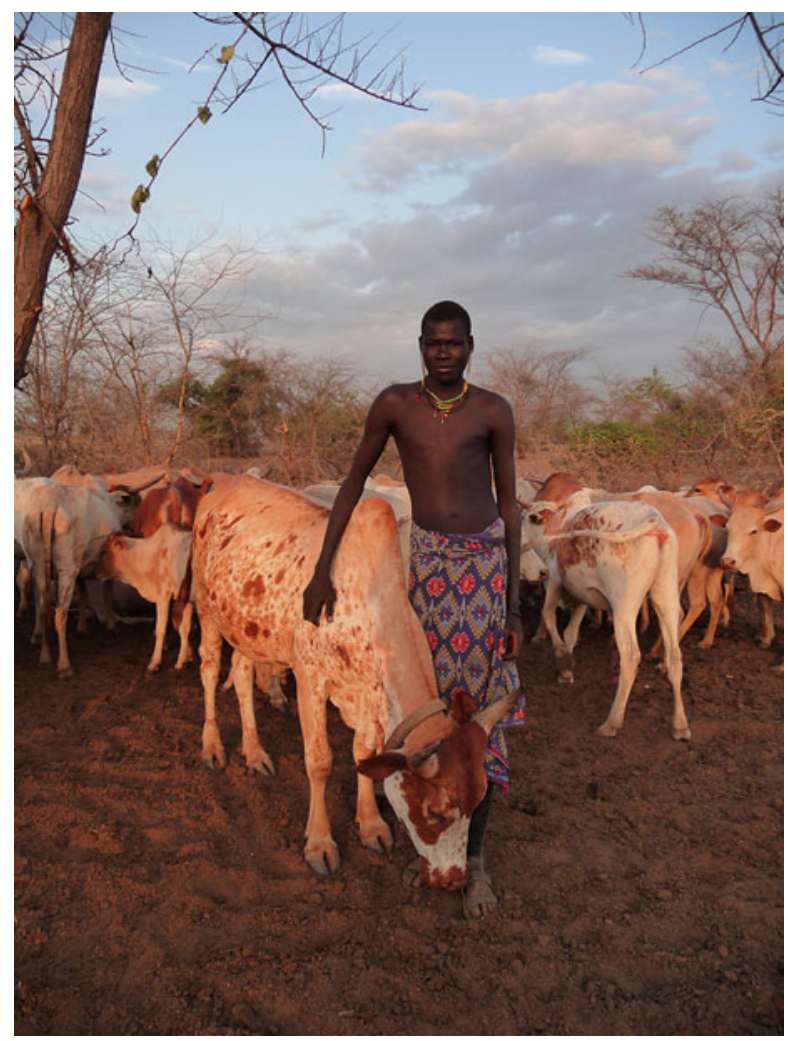


of the pastoralists in South Omo, which necessarily implies the need for some ways and means of stationary sources of income for the then non-migratory population. In consequence enforced societal transformation will demand considerable conceptional architecture and research endeavor in order to accompany and facilitate these pathways into newly to be designed livelihood systems and outcomes. But, this should be noted: these at first sight completely new and seemingly culturally nonacceptable pathways are not to be taken as any purely unrealistic illusion! Already ten years ago and in the face of the above illustrated severe climate change induced droughts, had Nyangatom cattle herders started to sell cattle - at that time under disguise and hidden away from their fathers and elders (Troeger et al. 2012). Very obviously, processes of societal transformation were on the way - already at the beginning of the decade, to be enforced and accelerated by today's bundle of urges. Already at that time some members of the pastoral communities, especially the young men and women, were ready for processes of societal transformation. They were for example ready to abandon their culturally manifested and strict rule to not slaughter cattle except for religious reasons. The perspective of cattle feed would newly and additionally demand some readiness for societal transformation on the side of the pastoralists. The pastoralist cultural setting does by traditionally fixed rules not allow for any sale and ownership in capitalist terms, which would necessarily be one of the terms of sale and storage of cattle feed. - And at this point the question whether the climate service initiative in the outlined way would do good or harm must stay unanswered.

\section{Conclusion}

Concluding and turning back to the initially highlighted challenge envisioning societal transformation in terms of environmental justice realized with and for the inhabitants of the Lower Omo Valley in Ethiopia the chapter summarizes the argument in succession of the four environmental scales of analysis.

Very obviously do the forces on the global scale, the climate change imperative, threaten the livelihood system of pastoralism and the individual inhabitants of the pastoral lowlands in a way, which does not open any window of chance for a positive change. The pastoralists cannot but react on this threat by leaving the area with the cattle herd for seasons in succession with almost no way of return. In consequence of the given risky environment the people abandon their culturally inherited customs like the "culture of sharing" and try to survive as individual households and families, which is to be taken as a, if not fatal then at least highly damaging and un-just momentum of societal transformation.

The offer or challenge of decentralization and handing societal concerns, that is, governance, over to the people on the ground in the shape of committees does not offer any true chance of sustainable transformation. As the "state" governed committees do not open any room for recognitional and likewise procedural justice, and do neither acknowledge preexisting governance arrangements as well as worldviews, knowledges, or cultures nor safeguard feasible and acceptable ways of 
participation and decision making, these two dimensions of justice in societal transformation are not realized in any operational way. The process is to be taken as unsustainable.

Human rights focused critics of the Omo-Gibe basin, namely the Oakland Institute (2013), describe the effects of the upstream hydropower reservoir Gibe III and the land clearing for the Kuraz Sugar Development Project, that is, the forces at the regional scale, as a tragedy that has caused hunger and conflict. Again, and with relation to these forces, no justice in terms of recognition and installment procedures was and is granted to the people, the pastoralists on the ground, and as well constellations at this scale are to be taken as unsustainable.

Finally, the local scale in vision, the chapter turns against a too euphoric interpretation of the perspective of "transformations" in terms of climate services. Cattle feed from the residues of the sugar cane might offer some chance, maybe the only chance, for some partial loss compensation. But surely the more substantive aspects of a sustainable, which means a just handling of given situational settings, would need attention in the face of the claim for environmental and social justice:

- Which distributional effects will societal transformations have within the pastoralist societies? Who of the members of the pastoralist communities will be in the lead and govern the processes of feed storage, distribution and sale, and how will these subsequent leading social positions be legitimized?

- How will questions of societal justice, participation, and the distributive effects of climate change be addressed in social debates?

- Which changes in modes of governance and participation could be essential for any promising transformative processes?

\section{References}

Abbink $\mathrm{J}$ et al (2014) Lands of the future: transforming pastoral lands and livelihoods in eastern Africa. Working paper N0. 154. Max Planck Institute, Halle

Adger N, Paavola J, Huq S, Mace M (2006) Fairness in adaptation to climate change. MIT Press, Cambridge

Adger $\mathrm{N}$ et al (2009) Are there social limits to adaptation to climate change? Clim Chang 93:335-354

Appadurai A (1990) Disjuncture and difference in the global cultural economy. Theory Cult Soc $7(2-3): 295-310$

Ayele Z (2011) Local government in Ethiopia: still an apparatus of control? Law Democr Dev 15(1):1-27

Buffavand L (2016) 'The land does not like them': contesting dispossession in cosmological terms in Mela, South-West Ethiopia. J East Afr Stud 10(3):476-493

ESC (Ethiopian Sugar Corporation) (2014) Vision, Mission, Values. http://www.etsugar.gov.et/php/ en/about/vision-mission-values

European Commission (2014) www.climate-services.org/about-us/what-are-climate-services

Famine Early Warning Systems Network: https://fews.net/east-africa/ethiopia

FDRE (2012) South Omo Villagization plan. Federal Democratic Republic of Ethiopia, Addis Ababa 
Foucault M (1977) Dispositive der Macht. Über Sexualität, Wissen und Wahrheit. Merve-Verlag, Berlin

Hobold J et al (2019) Social-ecological change in the Omo-Turkana basin: a synthesis of current developments. Springer, without pages

Kamski B (2016) The Kuraz Sugar Project (KSDP) in Ethiopia: between 'sweet visions' and mounting challenges. J East Afr Stud 10(3):568-580

Kamski B (2019) Ethiopia Insight: Omo investors won't scrub away Kuraz's sugary stain. https:// www.ethiopia-insight.com/2019/08/01

Lefort R (2012) Free market economy, 'developmental state' and party state hegemony in Ethiopia: the case of the 'model farmers'. Afr Stud 50(4):681-706

Mouffe C (2013) Agonistics: thinking the world politically. Verso, London/New York

Mueller-Mahn D, Everts J, Stephan Ch (2018) Riskscapes revisited - exploring the relationship between risk, space and practice. Erdkunde 72:197-213

Omo Turkana Research Network OTuRN (2016) Briefing note I - The Kuraz Sugar Development Project, Michigan State University, 1-6

Rancière J (1998) Disagreement: politics and philosophy. University of Minnesota Press, Minneapolis

Regessa A, Hizekiel Y, Korf B (2019) 'Civilizing' the pastoral frontier: land grabbing, dispossession and coercive agrarian development in Ethiopia, University of Zurich

Schatzki T (2002) The site of the social: a philosophical account of the constitution of social life and change. The Pennsylvania State University Press, University Park

Schatzki T (2012) A primer on practices. In: Higgs J, Barnett R, Billet S, Hutchings M, Trede F (eds) Practice-based education: perspectives and strategies. Sense Publishers, Rotterdam, pp $13-26$

Stevenson EG, Buffavand L (2018) 'Do our bodies know their ways?' - Villagization, foodinsecurity, and ill-being in Ethiopia's Lower Omo Valley. Afr Stud Rev 61:109-133

Swyngedouw E (2011) Interrogating post-democratization: reclaiming egalitarian political spaces. Polit Geogr 30(7):370-380

Temper L, Walter M, Rodriguez I, Kothari A, Turhan E (2018) A perspective on radical transformations to sustainability: resistances, movements and alternatives. Sustain Sci 13:747-764

The Oakland Institute (2013) OMO: local tribes under threat, a field report from the Omo Valley, Ethiopia. Oakland

Troeger S (2016a) Societal transformation, buzzy perspectives towards successful climate change adaptation: an appeal to caution, Chapter 19. In: Filho WL et al (eds) Handbook of climate change adaptation. Climate change management - implementing climate change adaptation in cities and communities, integrating strategies and educational approaches. Climate change management series. Springer, Cham, pp 353-365

Troeger S (2016b \& 2018) 'Everything that is happening now is beyond our capacity' - Nyangatom livelihoods under threat, Chapter 19. In: Filho WL et al (eds) Climate change management series. Springer, pp 353-365. Republished in Cambridge University Press \& UNESCO: Indigenous knowledge for climate change assessment and adaptation, Chapter 15. Cambridge, pp 214-226

Troeger S (2018) 'Committees', a promising institution in climate change communication and adaptation? Chapter 22. In: Leal W et al (eds) Handbook of climate change communication. Climate change management, vol 2. Springer, Cham, pp 341-355

Troeger S et al (2012) Failing seasons, ailing societies - climate change and adaptation in Ethiopia. Addis Ababa

Turton D (1985) Mursi response to drought: some lessons for relief and rehabilitation. Afr Aff 84 (336):331-346

Turton D (2010) The downstream impact. Presentation at the School of Oriental and African Studies, University of London, organized by the Royal Africa Society. www.mursi.org www.climate-services.org/about-us/what-are-climate-services 
Open Access This chapter is licensed under the terms of the Creative Commons Attribution 4.0 International License (http://creativecommons.org/licenses/by/4.0/), which permits use, sharing, adaptation, distribution and reproduction in any medium or format, as long as you give appropriate credit to the original author(s) and the source, provide a link to the Creative Commons license and indicate if changes were made.

The images or other third party material in this chapter are included in the chapter's Creative Commons license, unless indicated otherwise in a credit line to the material. If material is not included in the chapter's Creative Commons license and your intended use is not permitted by statutory regulation or exceeds the permitted use, you will need to obtain permission directly from the copyright holder.

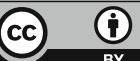

